\title{
Factors Influencing Enrollment in Higher Education: A Comparison of First and Second Generation Hispanic Students
}

\author{
Yesenia Garcia $^{1}$, Lori Kupczynski ${ }^{2} \&$ Marie-Anne Mundy ${ }^{2}$ \\ ${ }^{1}$ Zapata South Elementary School, Zapata County Independent School District, Zapata, Texas, USA \\ 2 Department of Educational Leadership and Counseling, Texas A\&M University-Kingsville, Kingsville, Texas, \\ USA \\ Correspondence: Lori Kupczynski, Department of Educational Leadership and Counseling, Texas A\&M \\ University-Kingsville, 700 University Blvd., MSC223, Kingsville, Texas, USA, Tel: 1-956-648-7617.
}

Received: October 20, 2015

doi:10.5430/irhe.v1n1p9
Accepted: November 3, 2015

Online Published: November 10, 2015

URL: http://dx.doi.org/10.5430/irhe.v1n1p9

\begin{abstract}
This study concentrated on first and second-generation Hispanic students' perception of higher education, parental support, degree of enculturation, and motivation having a direct correlation to students' pursuit of a post-secondary education. The information may have an impact on enrollment and retention in institutions of higher learning. The quantitative survey, Factors Influencing Hispanic Student Retention (FIHSR), was administered and analyzed to find differences between the studies subgroups: perceptions of higher education, parental support, degree of enculturation, and motivation among Hispanic students. The study found no significant difference in three of the four subgroups, perceptions of higher education, parental support, and degree of enculturation. Data analysis suggests Hispanic students feel a strong sense of ethnic pride. The final subgroup, motivation among Hispanic students, found a significant difference among collected data suggesting there may be a decrease in motivation as the degree of generation increases. Recommendations, for further study, may include a larger population sample, increased degree of generations, survey students from other Hispanic Serving Institutions, and conduct a comparison with non-Hispanic Serving Institutions within the state of Texas.
\end{abstract}

Keywords: Hispanic, generational status, Hispanic serving institution, higher education enrollment

\section{Introduction}

The Hispanic population is the fastest growing minority in the United States (U.S.); however, they lag behind other ethnic groups in post-secondary education enrollment, retention, and degree acquisition (Santiago, 2012). This occurrence creates a prevalent achievement gap which Hispanics have been unable to close (Saenz \& Ponjuan, 2009).

There has been an increase in the number of Hispanic Serving Institutions (HSIs) in areas with high Hispanic populations (Santiago, 2012). Santiago (2012) states that the invention of HSIs was based on efforts to better serve this growing minority. A group effort by HSIs, community leaders, and parents joining together may be the only manner in which the Hispanic education crisis may be averted by closing the achievement gap between minorities and Whites and diverting the detrimental economical effects of achievement gaps.

As the federal government tries to better serve students in post-secondary institutions, it sets new complex federal mandates requiring increased enrollment and retention rates. HSI must therefore explore different avenues to better serve the growing Hispanic populations. To serve these ends, HSIs may provide targeted services to first and second-generation students such as financial aid assistance and hiring faculty that become key role models, which in turn inspire and motivate Hispanic students. Additionally, previous studies have also shown parental support has a major impact on student perceptions of higher education, and student motivation to enroll and persist in an institution of higher learning (Arciniega, 2012, Saenz \& Ponjuan, 2009).

This study examines several aspects of Hispanic first and second-generation students. The purpose of this study is to examine the difference between first and second-generation students on perceptions, parental support, degree of enculturation, and motivation at a Hispanic university in south Texas. HSIs could offer targeted support by 
recognizing how important first and second-generation student needs are to the future well being of the country (Medina \& Posadas 2012).

The study proposes to identify factors and influences that contribute to the successful enrollment of Hispanic students in higher education in pursuit of a post-secondary education. A survey was conducted with first and second-generation college students in a south Texas higher education institution. The study concentrated on first and second-generation students' perception of higher education, parental support, degree of enculturation, and motivation among Hispanic students correlation to students' pursuit of a post secondary education. As such, this research seeks to examine first and second-generation students' perception's impact on enrollment and retention in institutions of higher learning.

\subsection{Material Studied}

The purpose of the McWhirter's (2007) article is to illustrate the differences in perceived problems by ethnicity, socio-economic status, and academic readiness of student and parental education. The author addresses the perceived notions of possible barriers to a postsecondary education between Mexican Americans and White adolescents in the United States.

\subsubsection{Gender}

Gender norms in every aspect of our society and family system contribute too much of the male issues discussed ("Gender Gap in Higher Education", 2010). Seanz and Ponjuan (2009) contend that males must meet the cultural expectations of working and contributing to provide for the family. The researchers (2009) point out that males in the Hispanic culture are taught about superior male roles at a very young age and are programmed to hide emotions. These actions impede young males in showing their true feelings and asking for help when it comes to their studies.

Saenz and Ponjuan (2009) argue that men are pigeon holed into postponing attaining a degree because they must meet Hispanic cultural expectations of being the breadwinner and helping sustain the household. Latino males have found new opportunities for those who were previously financially unable to pursue a post-secondary education (United States Department of Education, 2012). The financial and career incentive associated with military service may be influential when examining the perceptions of Latino males concerning higher education (Saenz \& Ponjuan, 2009).

Saenz and Ponjuan (2009) conclude that there are several factors that can contribute to a Latino male's success: 1) the role of Latino families and their communities, 2) Latino male leaders as mentors, and 3) the need to raise awareness to this complex issue at all levels of our society. Families, communities, and higher education institutions must inspire and provide direction and vision for Latino males regardless of generational background.

\subsubsection{Parental Involvement}

Noted authors focus on the importance of diverse forms of parental involvement and the power parents posses in helping to create educational events. The Mahoney and Kaiser (1999) study emphasizes the focus on parents being equal members on a team to intervene positively for student success. Parents should not be limited in teaching their children, but rather should be allowed to provide other types of knowledge that can help a child learn from diverse situations.

Other authors such as Vincent (1996) focus on the fact that parents do not participate in their children's education even after repeated invitations and a welcoming atmosphere. Parents of working-class children and minorities remain feeling disenfranchised from the school system in spite of the fact that in recent years the trend has changed, and more effort has been placed on bringing in parents from all walks of life.

De Gaetano (2007) contends that the nonexistent or low participation rates of Hispanic parents in their students' education has a direct correlation to the parents' mistrust of the school's bureaucracies, differences in parental expectations in the U.S. and native countries, negative attitudes from administrators and teachers regarding Latino parents, and language barriers which inhibit proper communication. The authors surmise that the "one size fits all" framework towards parental involvement is inadequate when trying to reach Latino parents. Parents of different cultural and socio-economic backgrounds have different needs and must each be approached with ethnic specific strategies in order to accommodate their needs (De Gaetano, 2007). The author further acknowledges that culture, ethnicity, and language must critically be understood, emphasized, and celebrated in order to fully reach parents, while empowering them in their child's learning. 


\subsubsection{Perceived Problems}

McWhirter's (2007) study indicated that there are perceived notions between White and Mexican American adolescents when it comes to finding solutions to financial issues, academic preparedness, and venturing away from home. Furthermore, the author states Mexican American students find it harder to venture away from home due to their cultural upbringing and parental perceptions towards fidelity to the core family unit. McWhirter (2007) also identifies that parental educational background and socioeconomic status greatly influences students' decision to attend a two or four year institution. The author concludes that students with educated parents are more likely to attend a four-year institution and find it easier to overcome perceived barriers, while students of lower socio-economic backgrounds and less educated parents find it harder to find solutions and overcome these same barriers.

The author further emphasizes the need for academically ready students coming from secondary schools and a college readiness culture. Students need to feel well prepared and informed in order to plan their future career goals and aspirations.

\subsubsection{Socioeconomic Status}

Boyer, Butner, and Smith, (2007) state that students of low socio-economic means feel more compelled than upper class students to finish their post-secondary education quickly because a university degree is less likely to be within their means. Socioeconomic background, however, can influence one's particular career choice or educational pathway. As a result, the authors conclude that colleges and universities should implement courses and programs that remediate those students not ready for the typical higher education curriculum. Remediation is an issue that is continuously in the minds of policymakers and educators (Gollnick \& Chinn, 2013).

\subsubsection{Resiliency}

Ceja's (2004) study on Chicana aspirations for a higher education is firmly based on parental support and their educational resiliency. The author states that positive encouragement by parents, the use of life experiences to promote a desire for a better life, and the Chicana resiliency even against socio-economic factors help them become successful in their quest to attaining a higher education.

The author argues that the parental encouragement and motivation to receive a higher education and avoid living a marginalized existence is a huge incentive for minority women who want to surpass their current situations. While their parents lacked the education, socio economic status, and knowledge of the school system, they were able to provide them, their daughters, with stories of lived experiences, which would serve as a warning while urging their children to reach greater success and educational attainment (Ceja, 2004).

Ceja (2004) used interviews to conduct a study, which provided a different view of the parental role in the Chicana educational life. The author used Chicana women from various higher educational institutions and interviewed them three times using their initial interview as their baseline for the study. Ceja (2004) concluded that these women all had similar answers to the question of the role their parents played in their education. Their parents gave them their full support and encouragement while reminding them of the many obstacles they faced to provide them with a better life due to their lack of education (Ceja, 2004). The author reiterates that the parents' strong desire to have their daughters transcend the poverty line, oppression, and discrimination is based on the belief that these things can be obtained through an education.

Ceja (2004) concludes that uneducated parents are not valued or recognized as they should be because of the misconception that they are not helpful in the process of guiding their children toward striving to attain a higher education. In reality, the author contends that they are an under-used and an under-addressed population within our schools and institutions of higher learning. It would behoove these institutions to help promote a culture of support and encouragement among this particular group (Ceja, 2004).

\subsubsection{Four Year versus Two-Year Institutions}

Roska (2011) identifies contributing factors to the disparity of students attaining a bachelor's degree from a four-year institution as compared to attaining an associates or certificate from a community college. The author notes in his study that students with intense job obligations while still attending a community college have a higher tendency to drop out and a low percentage of associate's degree completion. These students are usually from low socio-economic families, non-professional parents, and have full time jobs (Roksa, 2011). The author contends that students of low socio-economic means feel more compelled than students of a higher socio-economic level to finish their post secondary education quickly because a university degree is less likely to be within their means despite being valuable 
in attaining higher earnings. Students with low socio-economic backgrounds usually work because they have to supplement their income and their families', leaving them with minimal options (Roksa, 2011). As a result, Roksa (2011) expands the theory that low socio-economic students are left with the option of enrolling in a more affordable community college, and for the most part, working full time jobs to sustain their livelihoods.

\subsubsection{Hispanic Educational Programs}

Medina's and Posadas' (2012) study illustrates how Hispanic Serving Institutions (HSI) are responsible for educating the large majority of first generation and low socio-economic students within their institutions. The study shows that retention of these minority students means having faculty and staff that are sensitive to diverse cultures and provide academic and financial support for these students. Santiago (2012) states that the invention of a Hispanic serving institution was based on the effort to serve the growing minority. As the research delineates, with the different efforts of these institutions comes the realization that enrollment does not necessarily mean degree completion. There should be a progressive effort to support and hold institutions accountable for minority students enrolling and completing their degrees.

\section{Methods}

This research utilized a quantitative research method by gathering data from approximately 150 students which are first and second generation Hispanic students attending a Hispanic Serving Institution (HSI) in south Texas. This research analyzed the administered survey after it had been completed and collected. The school is currently a (HSI); providing Hispanic students with services, opportunities, and mentoring that will help them adjust to a post-secondary life.

This research study utilized a quasi-experimental survey design using post-test only with non-equivalent study groups. The survey examined first and second-generation students' perceptions, parental support, degree of enculturation, and motivation among Hispanic university students in south Texas. A one-way Analysis of Variance (ANOVA) was conducted to determine the differences between first and second-generation student perceptions on the importance of education, parental support, degree of enculturation, and motivation among Hispanic students.

\subsection{Population and Sample}

The population sample was comprised of 61 student surveys administered to college student participants who were first and second-generation college students during the 2014 fall semester in an HSI in rural south Texas. The gender of the population of the post-secondary institution was practically equal with a 53 percent male and 47 percent female enrollment. The campus was reflective of the area demographics and predominantly Hispanic. There was a 62 percent Hispanic population, 27 percent White, 5 percent African American, and approximately 6 percent international students.

\subsection{Instrumentation}

"Factors Influencing Hispanic Student Retention" (FIHSR) was the survey instrument utilized to collect the data from the research study. In the creation of the FISHR, the Personal and Academic Self-Concept Inventory (PASCI) and the Multi-group Ethnic Identity Measure (MEIM) developed by Phinney (1992) were used. The survey, consisting of demographic information and 5-point Likert items, was created and piloted in 2011 (Mundy, 2011). The validity of the instrument was determined using both a factor analysis as well as discussion with experts. Based on the outcome of the pilot, the survey was updated and new questions were added. The instrument has a Cronbach's Alpha reliability score of .80 . The survey is comprised of 52 questions. It was divided into five subgroups, which included: demographic questions, perceptions of education, enculturation, parental support, and motivation. The survey was administered and followed a Likert type scale, ranging from 1 (strongly disagree) to 4 (strongly agree) for demographic data, enculturation, and motivation.

\section{Results}

Hispanics encompassed $74 \%$ of the respondents to the survey. The majority of the respondents were $39 \% 1^{\text {st }}$ generation college students and $41 \% 2^{\text {nd }}$ generation. Parental education level data was also collected. Respondents' perceptions of attending college, as well as language spoken at home, and language spoken with friends were also collected. See Table 1 for a summary of demographic data. 
Table 1. Demographic data

\begin{tabular}{|c|c|c|c|}
\hline Characteristics & & $\mathrm{N}$ & Percentage \\
\hline \multicolumn{4}{|l|}{ Hispanic } \\
\hline & Yes & 52 & $74.3 \%$ \\
\hline & No & 9 & $12.9 \%$ \\
\hline \multicolumn{4}{|l|}{ Generation } \\
\hline & First Generation & 27 & $38.8 \%$ \\
\hline & Second Generation & 29 & $41.2 \%$ \\
\hline & Other & 5 & $7.1 \%$ \\
\hline \multicolumn{4}{|l|}{ Mother's Education Level } \\
\hline & Grade 1-6 & 2 & $3.3 \%$ \\
\hline & Grade 7-9 & 3 & $4.9 \%$ \\
\hline & Grade 9-12 & 12 & $19.7 \%$ \\
\hline & $\begin{array}{l}\text { Some College/ } \\
\text { Certificate Training }\end{array}$ & 19 & $31.1 \%$ \\
\hline & Associate's Degree & 13 & $21.3 \%$ \\
\hline & Bachelor's Degree & 8 & $13.1 \%$ \\
\hline & Graduate Degree & 4 & $6.6 \%$ \\
\hline \multicolumn{4}{|l|}{ Father's Education Level } \\
\hline & Grade 1-6 & 3 & $5.0 \%$ \\
\hline & Grade 7-9 & 2 & $3.3 \%$ \\
\hline & Grade 9-12 & 17 & $28.3 \%$ \\
\hline & $\begin{array}{l}\text { Some College/ } \\
\text { Certificate Training }\end{array}$ & 17 & $28.3 \%$ \\
\hline & Associate's Degree & 5 & $8.3 \%$ \\
\hline & Bachelor's Degree & 10 & $16.7 \%$ \\
\hline & Graduate Degree & 6 & $10.0 \%$ \\
\hline \multicolumn{4}{|l|}{ Attending College Perception } \\
\hline & Important & 15 & $21.4 \%$ \\
\hline & Very Important & 46 & $65.7 \%$ \\
\hline \multicolumn{4}{|l|}{ Language Spoken at Home } \\
\hline & Spanish Only & 9 & $12.9 \%$ \\
\hline & Spanish and English & 24 & $34.3 \%$ \\
\hline & English Only & 24 & $34.3 \%$ \\
\hline & Other & 4 & $5.7 \%$ \\
\hline \multirow[t]{4}{*}{ Language Spoken with Friends } & Spanish Only & & \\
\hline & Spanish and English & 23 & $32.9 \%$ \\
\hline & English Only & 36 & $51.4 \%$ \\
\hline & Other & 2 & $2.9 \%$ \\
\hline
\end{tabular}

The students' perceptions of self-efficacy in higher education demonstrated that participants are more concerned in areas of scholastic ability. Descriptive statistics are listed in Table 2. 
Table 2. Higher education

\begin{tabular}{|c|c|c|c|}
\hline & Median & Mean & $\begin{array}{l}\text { Standard } \\
\text { Deviation }\end{array}$ \\
\hline $\begin{array}{l}\text { When you have to read an essay and understand it for a class } \\
\text { assignment, how worried or concerned do you feel about it? }\end{array}$ & 4.000 & 3.966 & 2.1251 \\
\hline $\begin{array}{l}\text { When you have to write an argument to convince your teacher, } \\
\text { who may disagree with your ideas, how concerned or worried do } \\
\text { you feel about it? }\end{array}$ & 4.000 & 3.923 & 2.2303 \\
\hline $\begin{array}{l}\text { Compared with classmates, how often do you feel you must } \\
\text { study more than they do to get the same grades? }\end{array}$ & 5.000 & 4.458 & 2.0538 \\
\hline $\begin{array}{l}\text { In turning in a major assignment such as a term paper, how often } \\
\text { do you feel you did an excellent job on it? }\end{array}$ & 5.000 & 4.900 & 1.7631 \\
\hline $\begin{array}{l}\text { How often do you have trouble expressing your ideas when you } \\
\text { have to put them into writing as an assignment? }\end{array}$ & 4.000 & 3.763 & 1.8785 \\
\hline $\begin{array}{l}\text { How often do you have trouble-understanding things you read } \\
\text { for class assignments? }\end{array}$ & 3.000 & 3.237 & 1.8036 \\
\hline $\begin{array}{l}\text { How often do you imagine that you have less scholastic ability } \\
\text { than your classmates? }\end{array}$ & 3.000 & 3.333 & 2.1241 \\
\hline
\end{tabular}

Descriptive statistics for degree of enculturation in the subgroup data is listed in Table 3. It would appear that the majority of respondents displayed pride in their cultural background.

Table 3. Degree of enculturation

\begin{tabular}{llll}
\hline & Median & Mean & $\begin{array}{l}\text { Standard } \\
\text { Deviation }\end{array}$ \\
\hline I spend a lot of time with Hispanic students & 3.000 & 3.003 & .8227 \\
I spend a lot of time with students that are not Hispanic & 2.500 & 2.500 & .6244 \\
I have a lot of friends that are Hispanic students & 3.000 & 3.383 & .5849 \\
I have a lot of friends who are not Hispanic & 2.000 & 2.317 & .7009 \\
I am proud of my Hispanic background & 4.000 & 3.456 & .6288 \\
I am proud that I have assimilated well into the American culture & 3.000 & 3.283 & .5552 \\
My family is very traditional & 3.000 & 3.000 & .8025 \\
My family is very Americanized & 3.000 & 2.800 & .8193 \\
I have spent time trying to find out more about my ethnic group, & 2.000 & 2.441 & .8152 \\
such as its history, traditions, and customs & & & \\
I am active in organizations or social groups that include mostly & 2.000 & 2.407 & .7220 \\
members of my own ethnic group & & & \\
I think a lot about how my life will be affected by my ethnic group & 2.000 & 2.390 & .7432 \\
membership & & & \\
I have a clear sense of my ethnic background and what it means for & 3.000 & 2.983 & .6821 \\
me & & & \\
I am happy that I am a member of the ethnic group I belong to & 3.000 & 3.271 & .5196
\end{tabular}


I have a strong sense of belonging to my own ethnic group

I understand pretty well what my ethnic group membership means 3.000 to me

In order to learn more about my ethnic background, I have often talked to other people about my ethnic group

I have a lot of pride in my ethnic group

I participate in cultural practices of my own ethnic group, such as special food, music, or customs

I feel a strong attachment towards my own ethnic group

I feel good about my cultural or ethnic background

$\begin{array}{lll}3.000 & 3.167 & .7170 \\ 3.000 & 3.117 & .6662 \\ 3.000 & 2.617 & .8045 \\ 3.000 & 3.317 & .7247 \\ 3.000 & 3.150 & .8402 \\ 3.000 & 3.117 & .6911 \\ 3.000 & 3.407 & .5907\end{array}$

$3.117 \quad .6662$

$2.617 \quad .8045$

$3.317 \quad .7247$

402

911

The median, mean, and standard deviation was calculated for each question in the motivation subgroup and is presented in Table 4.

Table 4. Motivation

\begin{tabular}{|c|c|c|c|}
\hline & Median & Mean & Standard Deviation \\
\hline $\begin{array}{l}\text { I am more motivated to learn when I have the responsibility } \\
\text { for my learning activities }\end{array}$ & 3.000 & 3.367 & .6097 \\
\hline I am responsible for my learning & 4.000 & 3.567 & .5635 \\
\hline $\begin{array}{l}\text { I am responsible for my own actions and my success or } \\
\text { failure in school }\end{array}$ & 4.000 & 3.717 & .4903 \\
\hline $\begin{array}{l}\text { I am confident that I will be able to overcome obstacles to } \\
\text { my learning }\end{array}$ & 4.000 & 3.683 & .4691 \\
\hline How I do in class depends mainly on who my instructor is & 3.000 & 2.667 & .8165 \\
\hline $\begin{array}{l}\text { I make independent decisions, based on my own beliefs and } \\
\text { values }\end{array}$ & 4.000 & 3.633 & .5197 \\
\hline The decision to attend college was mine & 4.000 & 3.683 & .5964 \\
\hline $\begin{array}{l}\text { My parents weighed strongly on my decision to attend } \\
\text { college }\end{array}$ & 3.000 & 3.017 & .9654 \\
\hline My peers weighed strongly on my decision to attend college & 2.000 & 2.383 & .9931 \\
\hline $\begin{array}{l}\text { My parents discuss issues with me and treat me as an equal } \\
\text { adult }\end{array}$ & 3.000 & 3.183 & .8732 \\
\hline $\begin{array}{l}\text { Its important to think about the choices I am making about } \\
\text { my degree plan }\end{array}$ & 4.000 & 3.683 & .4691 \\
\hline $\begin{array}{l}\text { It is important to think about the courses I need to choose to } \\
\text { realize my career plans }\end{array}$ & 4.000 & 3.583 & .5302 \\
\hline I am really not too sure about what I want to do in the future & 2.000 & 2.033 & 1.0887 \\
\hline $\begin{array}{l}\text { It is important to consider if my present university course } \\
\text { choices are the right ones }\end{array}$ & 3.000 & 3.433 & .5928 \\
\hline $\begin{array}{l}\text { I always think hard about the steps I have to take in order to } \\
\text { be successful at school }\end{array}$ & 4.000 & 3.450 & .6490 \\
\hline $\begin{array}{l}\text { I am really not too sure about what program of studies I will } \\
\text { follow. I ask counselors for advice to improve my chances of } \\
\text { success }\end{array}$ & 2.000 & 2.254 & .9394 \\
\hline
\end{tabular}


Descriptive statistics were calculated for each question in the parental support subgroup, using a Likert type scale where 1 is support myself and 5 is family fully supports and are listed in Table 5.

Table 5. Parental support

\begin{tabular}{lccc}
\hline & Median & Mean & $\begin{array}{l}\text { Standard } \\
\text { Deviation }\end{array}$ \\
\hline $\begin{array}{l}\text { My level of financial support from my parents while } \\
\begin{array}{l}\text { I attend university } \\
\text { My level of emotional support from my parents }\end{array}\end{array}$ & & & \\
\begin{tabular}{l} 
while I attend university \\
\hline
\end{tabular} & 4.000 & 2.729 & 1.1270 \\
\end{tabular}

A one-way analysis of variance (ANOVA) was conducted to evaluate the difference among the generations of college students on education. The independent variable, generation, included three levels: first generation, second generation, and other. The dependent variable was a perception of self-efficacy in higher education. The ANOVA was not significant, $F(2,57)=.39, p=.68, \eta^{2}=.01$. The effect size was small with the generational factor accounting for $1 \%$ of the variance of perception of self-efficacy in higher education.

A one-way analysis of variance (ANOVA) was conducted to evaluate the differences among the generation of college attendance on the degree of enculturation. The independent variable, generation, included three levels: first generation, second generation, and other. The dependent variable was the degree of enculturation. The ANOVA was not significant, $F(2,57)=.39, p=.43 \eta^{2}=.03$ the effect size was small with the generational factor accounting for $3 \%$ of the variance of enculturation, as assessed by partial eta squared.

A one-way analysis of variance (ANOVA) was conducted to evaluate the differences among the generation of college attendance on the degree of motivation. The independent variable, generation, included three levels: first generation, second generation, and other. The dependent variable was the degree of motivation. The results of the ANOVA testing indicated there was a significant difference between first and second-generation students on the perception of motivation among Hispanic university students, $F(2,57)=5.0 ; p=.01, \eta^{2}=.15$. The effect size was considered large with the generational factor accounting for $15 \%$ of the variance of motivation, as assessed by partial eta squared. The means and standard deviation for the independent variables first generation, second generation, and other were calculated. The motivation for first generations appears larger $(\mathrm{M}=77.9 ; \mathrm{SD}=12.39)$ than other generations $(M=63.4 ; \mathrm{SD}=5.4)$. The motivation between second generations $(\mathrm{M}=80.57 ; \mathrm{SD}=10.52)$ was larger than other generations $(\mathrm{M}=63.4 ; \mathrm{SD}=5.4)$. This suggests that student's motivation decreases with parents of higher education generation.

A significant difference was found between generations on student motivation with the generational factor accounting for $15 \%$ of the variance. This was considered a moderately large effect size.

A one-way analysis of variance (ANOVA) was conducted to evaluate the relationship among the generation of college attendance on the degree of parental support. The independent variable, generation, included three levels: first generation, second generation, and other the dependent variable was the degree of parental support. The ANOVA was not significant, $F(2,57)=.53, p=.59, \eta^{2}=.01$. The strength of the relationship was small among the generations on parental support, as assessed by partial eta squared was small, with the generational factor accounting for $1 \%$ of the variance of parental support. 
Inferential statistic data is listed in Tables 6 and 7.

Table 6. Dependent variables

\begin{tabular}{lllll}
\hline Variable & Degrees of Freedom & $\mathrm{F}$ & $\mathrm{p}$ & $\eta^{2}$ \\
\hline Higher Education & 2,57 & .39 & .68 & .01 \\
& & & & \\
Parental Support & 2,57 & .53 & .59 & .01 \\
Enculturation & 2,57 & .43 & .03 & .03 \\
Motivation & 2,57 & .01 & .01 & .15 \\
\hline
\end{tabular}

Table 7. Independent variables

\begin{tabular}{|c|c|c|c|c|c|c|c|c|}
\hline \multirow[t]{2}{*}{ Variable } & \multicolumn{2}{|c|}{ Higher Education } & \multicolumn{2}{|c|}{ Parental Support } & \multicolumn{2}{|c|}{ Enculturation } & \multicolumn{2}{|c|}{ Motivation } \\
\hline & M & SD & M & SD & M & SD & M & SD \\
\hline First Generation & 4.741 & .446 & 7.074 & 1.542 & 64.222 & 8.590 & 77.888 & 12.388 \\
\hline Second Generation & 4.786 & .417 & 7.535 & 1.933 & 63.928 & 5.449 & 80.571 & 10.528 \\
\hline Other & 4.600 & .547 & 7.000 & 2.121 & 59.800 & 4.324 & 63.400 & 5.412 \\
\hline
\end{tabular}

\section{Conclusion}

No significant difference was found between generations on student's perception of higher education with the generational factor accounting for $1 \%$ of the effect size. No significant difference was found between generations on student degree of enculturation with the generational factor accounting for $3 \%$ of the variance. No significant difference was found between generations on perceived parental support with the generational factor accounting for $1 \%$ of the variance. A significant difference was found between generations on student motivation with the generational factor accounting for $15 \%$ of the variance. This was considered a moderately large effect size. It would appear that student's decision to attend a post secondary institution was greatly influenced by their peers.

\subsection{Implications for Practice}

The results of this study contribute to higher education institutions seeking to provide optimal assistance to Hispanic students. Contributions to literature encompass the generation factor, which contributes to student's perception of motivation, enculturation, and parental support. It appears a strong sense of pride in their Hispanic culture shows a high degree of enculturation.

A further examination of the variable that included first generation, second generation, and other should be studied and modified to include third and fourth generations. Further generational factors could shed light on the decreased motivation Hispanic students encounter in attaining a higher education and how ambiguity in their future career plans and peers influence their decision-making.

\subsection{Recommendation for Further Research}

After analyzing the results, the data showed additional research possibilities: 
1) Further research with a larger sample size.

2) Future Research with a large sample size specifically examining $3^{\text {rd }}, 4^{\text {th }}$ and higher generational degrees.

3) Future research with third generation, which would encompass children with at least one parent and one grandparent with a college education.

4) Future research with fourth generations, which would encompass children with at least one parent, one grandparent, and great grandparent with a college education.

5) Further research on other Hispanic Serving Institutions along the southern border of Texas.

6) Further research with non-HSIs in various areas in Northern Texas.

7) Future research on enculturation and its impact on degree attainment for Hispanic students.

\section{References}

Arciniega, T. A. (2012). The crucial role of Hispanic-serving institutions in the education of Latino/a youth. Journal of Latinos and Education, 11(3), 150-156.

Boyer, P., Butner, B., \& Smith, D. (2007). A portrait of remedial instruction: Faculty workload and assessment techniques. Higher Education, 54(4), 605-613. http://dx.doi.org/10.1007/s10734-006-9030-8

Ceja, M. (2004). Chicana college aspirations and the role of parents: Developing educational resiliency. Journal of Hispanic Higher Education, 3(4), 338-362. http://dx.doi.org/10.1177/1538192704268428

De Gaetano, Y. (2007). The role of culture in engaging Latino parents' involvement in school. Urban Education, 42(2), 145-162.

Gollnick, D. M., \& Chinn, P. C. (2013). Multicultural education in a pluralistic society $\left(^{\text {th }}\right.$ ed.). New York: Prentice Hall.

Mahoney, G., \& Kaiser, A. (1999). Parent education in early intervention: A call for a renewed focus. Topics in Early Childhood Special Education, 19(3), 131.

McWhirter, E. (2007). Perceived barriers and postsecondary plans in Mexican American and White adolescents. Journal of Career Assessment, 15(1), 119-138.

Medina, C. A., \& Posadas, C. E. (2012). Hispanic student experiences at a Hispanic-serving institution: Strong voices, key message. Journal of Latinos and Education, 11(3), 182-188.

Mundy, M. A. (2011). Factors Influencing Hispanic Student Retention. Unpublished Manuscript.

Phinney, J. (1992). The multigroup ethnic identity measure: A new scale for use with adolescents and young adults from diverse groups. Journal of Adolescent Research, 7, 156-176.

Roksa, J. (2011). Differentiation and work: Inequality in degree attainment in U.S. higher education. Higher Education, 61(3), 293-308. http://dx.doi.org/10.1007/s10734-010-9378-7

Saenz, V., \& Ponjuan, L. (2009). The vanishing Latino male in higher education. Journal of Hispanic Higher Education, 8(1), 54-89.

Santiago, D. A. (2012). Public policy and Hispanic-serving institutions: From invention to accountability. Journal of Latinos and Education, 11(3), 163-167.

Vincent, C. (1996). Parent empowerment? Collective action and inaction in education. Oxford Review of Education, $22(4), 465$. 